\title{
Article \\ Pomegranate Juice Ameliorates Dopamine Release and Behavioral Deficits in a Rat Model of Parkinson's Disease
}

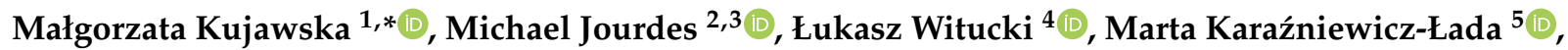

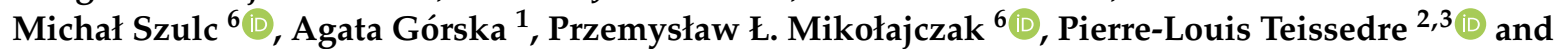 \\ Jadwiga Jodynis-Liebert ${ }^{1}$ (i)
}

Citation: Kujawska, M.; Jourdes, M.; Witucki, Ł.; Karaźniewicz-Łada, M.; Szulc, M.; Górska, A.; Mikołajczak, P.Ł.; Teissedre, P.-L.; Jodynis-Liebert, J. Pomegranate Juice Ameliorates Dopamine Release and Behavioral Deficits in a Rat Model of Parkinson's Disease. Brain Sci. 2021, 11, 1127. https://doi.org/10.3390/ brainsci11091127

Academic Editors: Carla Masala and Paolo Solla

Received: 20 July 2021

Accepted: 22 August 2021

Published: 25 August 2021

Publisher's Note: MDPI stays neutral with regard to jurisdictional claims in published maps and institutional affiliations.

Copyright: (c) 2021 by the authors. Licensee MDPI, Basel, Switzerland. This article is an open access article distributed under the terms and conditions of the Creative Commons Attribution (CC BY) license (https:// creativecommons.org/licenses/by/ $4.0 /)$.
1 Department of Toxicology, Poznan University of Medical Sciences, Dojazd 30, 60-631 Poznań, Poland; agorskaaga@gmail.com (A.G.); liebert@ump.edu.pl (J.J.-L.)

2 Institut des Sciences de la Vigne et du Vin, Université de Bordeaux, EA 4577, Enologie, 210 Chemin de Leysotte, F-33140 Villenave d'Ornon, France; michael.jourdes@u-bordeaux.fr (M.J.); pierre-louis.teissedre@u-bordeaux.fr (P.-L.T.)

3 Institut des Sciences de la Vigne et du Vin, INRA, USC 1366 INRA, IPB, 210 Chemin de Leysotte, F-33140 Villenave d'Ornon, France

4 Department of Biochemistry and Biotechnology, Poznan University of Life Sciences, Dojazd 11, 60-632 Poznań, Poland; lukwitucki@gmail.com

5 Department of Physical Pharmacy and Pharmacokinetics, Poznan University of Medical Sciences, Święcickiego 6, 60-781 Poznań, Poland; mkaraz@ump.edu.pl

6 Department of Pharmacology, Poznan University of Medical Sciences, Rokietnicka 5a, 60-806 Poznań, Poland; mszulc@ump.edu.pl (M.S.); przemmik@ump.edu.pl (P.Ł.M.)

* Correspondence: kujawska@ump.edu.pl; Tel.: +48-61-847-20-81 (ext. 156)

Abstract: Pomegranate juice (PJ) is a rich source of ellagitannins (ETs), precursors of colonic metabolite urolithin A, which are believed to contribute to pomegranate's neuroprotective effect. While many experimental studies involving PJ's role in Alzheimer's disease and hypoxic-ischemic brain injury have been conducted, our knowledge of pomegranate's effects against Parkinson's disease (PD) is very limited. Previously, we have reported that PJ treatment improved postural stability, which correlated well with enhancement of neuronal survival, protection against oxidative damage, and $\alpha$-synuclein aggregation. Since olfactory and motor deficits are typical symptoms of PD, in this study, we aimed to investigate the capability of PJ to protect against olfactory, motoric, and neurochemical alterations. To evaluate its efficiency, Wistar rats were given a combined treatment with ROT (1.3 mg/kg b.w./day, s.c.) and PJ (500 mg/kg/day, p.o.) for 35 days. After this, we assessed the olfactory discrimination index (DI) and vertical and horizontal activities as well as levels of dopamine and its main metabolite 3,4-Dihydroxyphenylacetic acid (DOPAC) in the dissected midbrain of animals. Our findings provide the first evidence that PJ treatment protects against ROT-induced DA depletion in the midbrain, which correlates well with improved olfactory function and vertical activity as well as with the presence of urolithin A in the brain.

Keywords: pomegranate juice; urolithin; ellagitannins; dopamine; olfactory impairment; $\alpha$-synuclein; non-motor symptoms; motor symptoms; Parkinson's disease

\section{Introduction}

Parkinson's disease (PD) is the second most common human neurodegenerative disorder after Alzheimer's disease (AD). It is a multi-attribute, debilitating condition that leads to significant disabilities and is related to a decreased quality of life over time. The pathological hallmark of PD is intracellular inclusions of misfolded $\alpha$-synuclein, called Lewy bodies, in the neurons of affected brain regions. Specifically, dopaminergic (DAergic) neurons in the substantia nigra pars compacta (SNpc) undergo degeneration resulting in dopamine (DA) deficiency and multiple other biochemical deficits in the nigrostriatal system [1]. As we previously reviewed, misfolded $\alpha$-synuclein spreads in a 
prion-like fashion to different brain regions, giving rise to successive non-motor and motor symptoms [2]. The presence of Lewy bodies in the olfactory bulb and olfactory tract has also been demonstrated [3]. Clinically, PD is characterized by motor dysfunctions such as bradykinesia, rigidity, tremor at rest, postural instability, and non-motor manifestations, including olfactory impairment, pain, autonomic dysfunction, sleep disturbance, fatigue, and behavioral changes $[1,3]$. Specifically, olfactory impairment precedes the onset of motor symptoms by years [4] and can be used to predict the occurrence of PD in asymptomatic individuals and to differentiate PD from other neurologic disorders [5].

Studies in both a toxin-based [6-8] and a transgenic mouse model of PD [9] have presented data suggesting the occurrence of a correlation between the density of nigral DAergic neurons and olfactory discrimination capacity. This association is supported by the findings of Höglinger et al. (2015) demonstrating that there is a direct axonal DAergic projection from the SNpc to the olfactory bulb of rats. The authors suggested that the neurotoxin-induced retrograde degeneration of DAergic neurons in this area could promote the observed hyposmia in rats [10].

In a large case-control study, Belvisi et al. (2020) identified factors inducing PD development: exposure to toxic agents such as pesticides, oils, and metals as well as dyspepsia and general anesthesia. The preventing action has been demonstrated for cigarette smoking, coffee drinking, and physical exercise. No data about the protective effects of medicinal plants have been found in available literature [11].

The pomegranate (Punica granatum L.) fruit is rich in various phytochemicals, including ellagitannins (ETs), exerting a wide range of biological activities such as antioxidative, anti-inflammatory, and antiapoptotic activities, which are believed to exert a significant role in its health benefits $[12,13]$. The neuroprotective effect of pomegranate phytochemicals has been demonstrated against hypoxia-ischemia (H-I) $[14,15]$ and cerebral ischemiareperfusion (I/R) brain injuries [16]. Regarding neurodegenerative diseases, a lot of in vivo studies on beneficial effects of pomegranate have been devoted to AD [17-23]; however, its neuroprotective potential against PD is based on very limited data $[13,24,25]$. We recently suggested that pomegranate's neuroprotective effect is mediated by urolithin A (UA) - a colonic microbiota ETs-derived metabolite [13]. This is supported by further studies demonstrating the alleviation of cognitive impairments upon treatment with UA in different in vivo models of neurodegeneration [26-28].

Previously, we have reported neuroprotective effects of pomegranate juice (PJ) in a rat model of PD based on prolonged low-dose rotenone treatment, which was manifested by improved postural stability correlating well with enhancement of neuronal survival in the $\mathrm{SN}$, protection against oxidative damage, and $\alpha$-synuclein aggregation in the midbrain. Since olfactory and motor deficits are typical symptoms of PD associated with a decreased DA level, in this study, we aimed to investigate the capability of PJ for counteracting these alterations in the rotenone model of PD and examine whether it is associated with the presence of UA in the brain.

\section{Materials and Methods}

\subsection{Animals}

The experiment was performed on six-week-old male albino Wistar rats (250-300 g) bred at the Department of Toxicology of the Poznan University of Medical Sciences (Poznań, Poland). The animals were held (four rats/cage) in polycarbonate cages (Techniplast, Varese, Italy) with wood shavings in a room maintained under a $12 \mathrm{~h} \mathrm{light} / 12 \mathrm{~h}$ dark cycle, $22 \pm 2{ }^{\circ} \mathrm{C}, 40-54 \%$ relative humidity, and controlled circulation of air. All groups were provided with a commercial diet (ISO 20000 certified laboratory feed Labofeed $\mathrm{H}$ ) and drinking water ad libitum.

\subsection{Experimental Design}

In order to induce PD in rats, rotenone (ROT, Sigma-Aldrich, Poznań, Poland) was injected subcutaneously once daily for 35 days in a dose of $1.3 \mathrm{mg} / \mathrm{kg}$ body weight [13]. 
Thirty-eight rats were divided randomly into four groups (8 animals in each group plus 3 animals in each of the groups treated with PJ for UA determination in the brain). Group I: rats receiving water (i.g.) and helianthi oleum raffinatum (FAGRON a.s., Olomouc, Czech Republic) (s.c.) from the 11th day, designated as a control group (Control). Group II: rats which were treated only with PJ at a dose of $500 \mathrm{mg} / \mathrm{kg} \mathrm{b.w./day} \mathrm{(i.g.)} \mathrm{and} \mathrm{injected}$ with helianthi oleum raffinatum from day 11 , referred to as the PJ-treated group (PJ). We used commercial 6-fold concentrated pomegranate juice obtained from Alter Medica (Żywiec, Poland) and characterized previously in our laboratory [13]. Group III: rats receiving water (i.g.) and injected with ROT in helianthi oleum raffinatum $(1.3 \mathrm{mg} / \mathrm{kg}$ b.w./day, s.c.) alone from the 11th day of the experiment, designated as the rotenone group (ROT). Group IV: rats treated with PJ $500 \mathrm{mg} / \mathrm{kg}$ b.w./day (i.g.) and injected with ROT from the 11th day, designated as the PJ+ROT group. The experiment lasted 45 days, including 10 days of pre-treatment with PJ and 35 days of combined treatment with PJ and ROT. Twenty-four hours after the last treatment, the rats were anesthetized with ketamine/xylazine (100 U/7.5 mg/kg b.w., intraperitoneally), and blood was withdrawn from the heart (Figure 1). After intracardiac perfusion with isotonic sodium chloride solution, the brain was quickly removed, and the midbrain was dissected on ice, and then snap-frozen with dry ice and stored at $-80^{\circ} \mathrm{C}$ until further use. For the purpose of UA determination in the brain, whole brains of three rats from groups II and IV were harvested after whole-body perfusion with phosphate-buffered saline, $\mathrm{pH}$ 7.4, to avoid overlapping of metabolites from the residual blood.

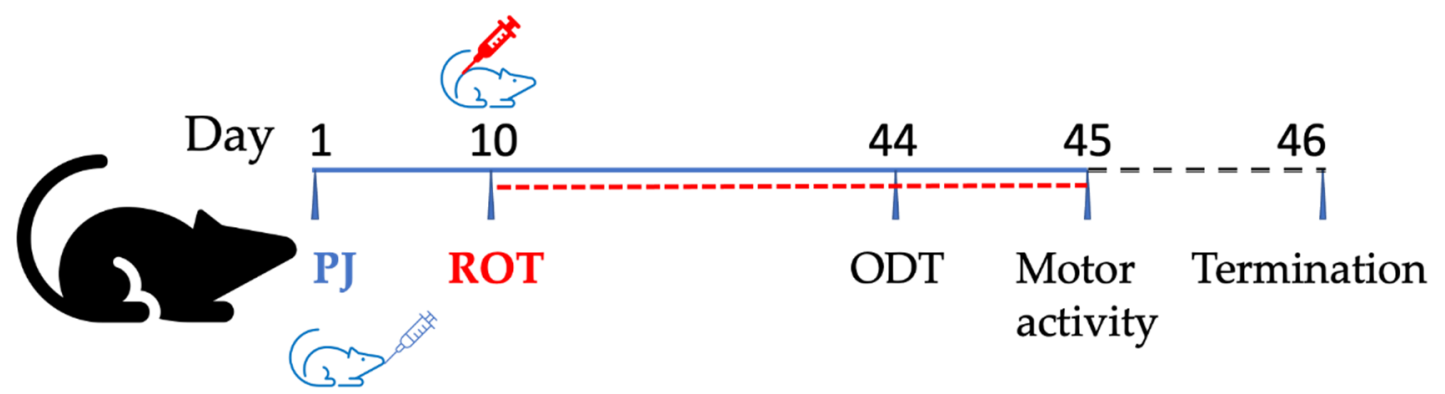

Figure 1. Graphical presentation of the experimental design used in the study.

\subsection{Behavioural Tests}

All tests were carried out between 11:00 and 15:00 and $24 \mathrm{~h}$ (motor activity) and $48 \mathrm{~h}$ (olfactory discrimination task) before the termination of the experiment in a behavioral testing facility (Figure 1).

\subsubsection{Motor Activity}

The activity of animals was assessed using an activity cage $(40 \mathrm{~cm} \times 40 \mathrm{~cm} \times 31 \mathrm{~cm})$ supplied with infrared beam emitters (Activity Cage 7441, Ugo Basile, Italy) combined with a counter measuring the number of photobeam crossings separately in the horizontal and vertical areas. After previous habituation in the experimental room, the animals were placed in the activity cage, and the examination was performed for $5 \mathrm{~min}$. Software analysis enabled the measurement of the horizontal and vertical activity of the rats.

\subsubsection{Olfactory Discrimination Task (ODT)}

This test was described by Rodrigues et al. (2014). We used a rectangular box $(60 \mathrm{~cm} \times$ $40 \mathrm{~cm} \times 50 \mathrm{~cm}$ ) with two interconnected compartments allowing animals free movement. Before testing, the rats were free to explore the apparatus for $5 \mathrm{~min}$. During the test, one compartment was loaded with sawdust with an odor familiar to the animal as it was exposed to the same animals during the preceding $48 \mathrm{~h}$. The second one, endowed with clean sawdust, was designated as a non-familiar odor. After placing a rat in the centrum of the box, the exploratory behavior in the compartments was recorded for $5 \mathrm{~min}$. The animal with olfactory impairment indicating an absence of discrimination tended to explore both 
compartments equally, while where the olfactory function was intact, the animals preferred to explore a particular compartment [7].

The discrimination index (DI) was calculated by dividing the difference in exploration time between the two compartments (non-familiar - familiar) by the total exploration time for both compartments (non-familiar + familiar). DI was expressed as a percentage, where positive and negative scores correspond to a preference towards non-familiar and familiar odors, respectively. The direction of changes was not considered in the statistical analysis.

\subsection{Dopamine (DA) and 3,4-Dihydroxyphenylacetic Acid (DOPAC) Level Determination}

\subsubsection{Isolation}

The midbrain tissue was homogenized with an extracting mixture containing acetonitrile-0.1 M HCl-27 mM EDTA water solution (50:40:10) at a weight: volume ratio of 1:10, using a handheld tissue homogenizer and subsequently sonicated for $20 \mathrm{~min}$ at 4 ${ }^{\circ} \mathrm{C}$. Then, the sample was centrifuged at $6500 \times g$, and the supernatant was filtered on a 0.2 mm PTFE microfilter before HPLC-MS analysis [29].

\subsubsection{UPLC-MS/MS Analysis}

The analysis of DA and DOPAC was performed on a Shimadzu Nexera (Shimadzu Co., Kyoto, Japan) chromatograph which contained a five-channel degasser (DGU-20A5) and thermostatted autosampler (SIL-30AC). MS detection was performed on a triple quadrupole mass spectrometer, the LCMS-8030 (Shimadzu Co., Kyoto, Japan). For data processing, the Lab solutions Series Workstation system (Shimadzu, Kyoto, Japan) was applied.

DA and DOPAC were separated in a Gemini ${ }^{\circledR}$ C18 analytical column $(150 \mathrm{~mm} \times$ $2 \mathrm{~mm}$ ) equipped with a security guard cartridge (Phenomenex, Torrance, CA, USA). The column temperature of $25^{\circ} \mathrm{C}$ was maintained by a column oven (Shimadzu ${ }^{\circledR}$ Model CTO2AC). The mobile phase was a mixture of an aqueous solution of acetic acid of $\mathrm{Ph}=2$ (A) and methanol (B). The following gradient elution was used: $0-3 \mathrm{~min} 5 \% \mathrm{~B}, 3-5 \mathrm{~min}$ linear increase to $70 \%, 5-8 \mathrm{~min} 70 \% \mathrm{~B}, 8-10 \mathrm{~min}$ linear decrease to $5 \%, 10-12 \mathrm{~min} 5 \% \mathrm{~B}$. The mobile phase flow rate was $0.15 \mathrm{~mL} / \mathrm{min}$, and the injected sample volume was $20 \mu \mathrm{L}$. The eluent from the UPLC column was introduced to the MS detector using electrospray ionization in positive ion mode for the measurement of $\mathrm{DA}$, and in negative ion mode for the measurement of DOPAC. The electrospray needle voltage was $4.5 \mathrm{kV}$. The desolvation line, the heat block temperature, and the interface temperature were maintained at $250{ }^{\circ} \mathrm{C}$, $400{ }^{\circ} \mathrm{C}$, and $350{ }^{\circ} \mathrm{C}$, respectively. Nitrogen was used as the nebulizing gas and as the drying gas with flow rates of 2 and $10 \mathrm{~L} / \mathrm{min}$, respectively. The most sensitive mass transition was from $m / z 154.1$ to 136.9 for DA and from $m / z 167.1$ to 123 for DOPAC. Linearity of the method was confirmed in the ranges of $0.5-10 \mathrm{ng} / \mathrm{mL}$ for DA and DOPAC. The within-run and between-run precision, expressed as relative standard deviations, was $<13.7 \%$ for DA and $<14.8 \%$ for DOPAC. The within-run and between-run accuracy of the method, expressed as the relative error, was $<14.5 \%$.

\subsection{Urolithin A Determination}

The brains of three rats harvested from each group treated with PJ (group II and IV) were extracted with methanol: $\mathrm{HCl}(99.9: 0.1 \mathrm{v} / \mathrm{v})$ following enzymatic hydrolysis of conjugated UA metabolites according to Núñez-Sánchez et al. (2014) and Seeram et al. (2006) with some modifications as we described previously [13,30,31]. To assess the concentration of UA in brain homogenates, UPLC-ESI-QTOF-MS analysis was performed, and a calibration curve was established using commercially available UA in the range of $1 \mathrm{ng} / \mathrm{mL}$ to $100 \mathrm{ng} / \mathrm{mL}$ according to the procedure described previously [13].

\subsection{Statistical Analyses}

The results are presented as mean values \pm SEM. Duplicate measurements were carried out, and 8 animals per experimental group were used. For the analysis of UA distribution, 3 animals were used. The control and ROT groups were compared by one- 
way analysis of variance (ANOVA) followed by Fisher's LSD test. The threshold for statistical significance was at $p<0.05$. All statistical analyses and charts were performed using PRISM 8.0 software (GraphPad Software Inc., La Jolla, CA, USA).

\section{Results}

\subsection{Behavioural Tests}

\subsubsection{Motor Activity}

Animals injected with rotenone exhibited statistically significant (77\% and $89 \%)$ lower horizontal and vertical activities, respectively, compared with the Control (Figure 2). Pomegranate juice administration to the ROT-challenged animals attenuated the motor deficit by increasing vertical activity by $160 \%$. A non-significant trend towards increased horizontal activity by $57 \%$ was also observed in these animals compared to the ROT group.

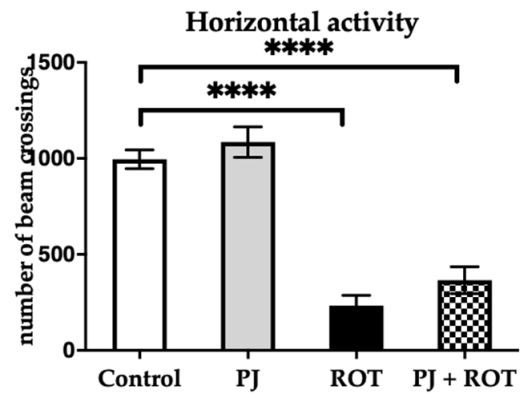

(a)

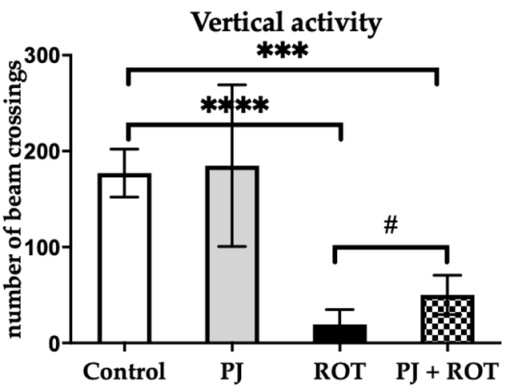

(b)

Figure 2. Effect of pomegranate juice treatment (PJ) on: (a) horizontal activity; (b) vertical activity in rotenone (ROT)-injected rats. Data are presented as mean values \pm SEM of eight rats per group and analyzed using one-way analysis of variance (ANOVA) followed by Fisher's LSD test. ${ }^{* * * *} p<0.0001$ vs. Control; ${ }^{* * *} p<0.001$ vs. Control B; $\# p<0.05$ vs. ROT.

\subsubsection{Olfactory Discrimination Task (ODT)}

As depicted in Figure 3, rats injected with ROT exhibited impairment of olfactory function attributed to the significantly decreased DI compared to control animals. Treatment with PJ mitigated this ROT-induced effect seen as an increase in DI compared to the ROT group, to the level observed in control animals. Interestingly, the rats receiving PJ and ROT, like the control rats, also showed a preference for the non-familiar odor, inferred from the positive DI scores.

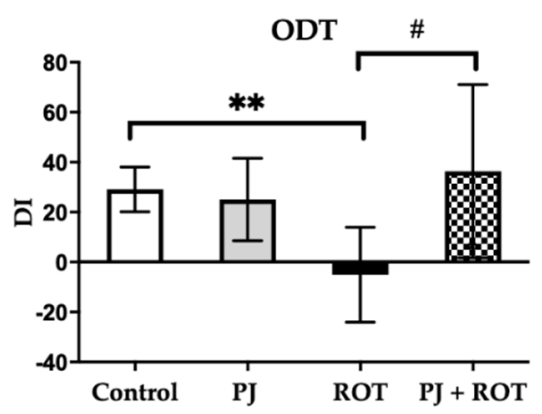

Figure 3. Effect of pomegranate juice treatment (PJ) on olfactory discrimination task (ODT) expressed as olfactory discrimination index (DI) in rotenone (ROT)-injected rats. Data are presented as mean values \pm SEM of eight rats per group and analyzed using one-way analysis of variance (ANOVA) followed by Fisher's LSD test. ${ }^{* *} p<0.01$ vs. Control. \# $p<0.05$ vs. ROT.

\subsection{Dopamine (DA) and 3,4-Dihydroxyphenylacetic Acid (DOPAC) Level}

Chronic exposure to ROT reduced dopamine (DA) and its metabolite DOPAC levels by $44 \%$ and $43 \%$, respectively, in the midbrain (Figure 4 ). However, the midbrain DA and 
DOPAC depletion was significantly attenuated by combined treatment with PJ and ROT, by $73 \%$ and $134 \%$, respectively (Figure 4 ).

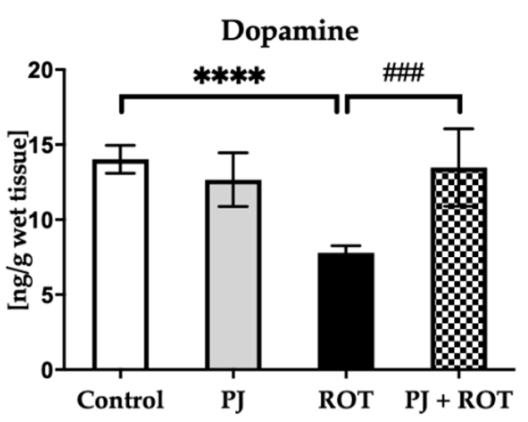

(a)

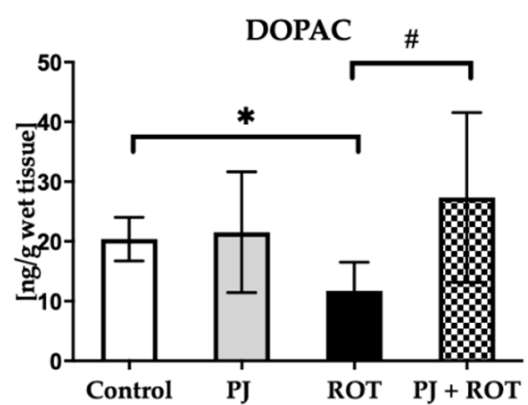

(b)

Figure 4. Effect of pomegranate juice treatment (PJ) on: (a) dopamine (DA); (b) DOPAC levels in the midbrains of rotenone (ROT)-injected rats. Data are presented as mean values \pm SEM of eight rats per group and analyzed using one-way analysis of variance (ANOVA) followed by Fisher's LSD test. **** $p<0.0001$ vs. Control; ${ }^{*} p<0.05$ vs. Control, \#\#\# $p<0.001$ vs. ROT; $\# p<0.05$ vs. ROT.

\subsection{Urolithin A Level}

The concentrations of $\mathrm{UA}$ in the brains of rats treated with $\mathrm{PJ}$ alone and in combination with ROT were $2068 \pm 0.274 \mathrm{ng} / \mathrm{g}$ wet tissue and $0.635 \pm 0.174 \mathrm{ng} / \mathrm{g}$ wet tissue, respectively, calculated as a mean value \pm SD of three rats from the relevant groups.

\section{Discussion}

Although the incidence and prevalence of PD have increased rapidly throughout the world, therapeutic options are still very disappointing, and available therapies treat only the symptoms of the disease. Thus, the optimal management of the neurodegenerative condition is postulated as requiring a multidisciplinary team approach, also encompassing an increasing number of non-pharmacological interventions [32].

The study presented herein is a continuation of the research tackling the question of whether PJ treatment can provide neuroprotection against PD. In rats, long-term exposure to low doses of rotenone, due to sustained inhibition of complex I, related oxidative injury, and $\alpha$-synuclein aggregation, induced developing degeneration of nigral DAergic neurons with histopathological hallmarks and PD-like symptoms [13,33,34]. DA depletion resulting from a loss of DAergic neurons in the SNpc is considered an important factor underlying the development of motor dysfunction in PD patients [1], which is reproducible in a rotenone PD model [33]. Nigrostriatal denervation is also manifested by a declined level of DOPAC, the main intra-neuronal metabolite of DA [35]. Since we previously observed that PJ offered protection against ROT-induced DAergic neurodegeneration, we therefore anticipated that administration of PJ might thereby mitigate DA depletion and related motor and non-motor deficits. In accordance with previous findings [36-39], low-dose treatment with ROT induced motor abnormalities manifested in our study, such as decreased horizontal and vertical activities, which were associated with a reduction in DA and DOPAC levels in the midbrain of rats. PJ administration restored the loss of DA level and its metabolite DOPAC, and slightly improved vertical activity. These findings corroborate previous results from Wei et al. (2020), who showed that treatment with ellagic acid (EA) resulted in improvements in the motor performance of rotenone-treated rats [40]. EA also has been reported to protect against 6-hydroxydopamine (6-OHDA) and lipopolysaccharide-induced DA neuronal damage and related motor impairment [41-44].

Despite the considerable number of studies devoted to the evaluation of neuroprotective effects by assessing motor behavior, very little research involving assessment of olfactory deficits has been conducted in experimental models of PD. Studies from toxininduced DAergic neuronal loss have shown that accumulation of abnormal $\alpha$-synuclein is 
not only confined to the $\mathrm{SN}$ but is also found in the olfactory tract [27,45]. Because PJ treatment protected against $\alpha$-synuclein cumulation in the brain in ROT-challenged rats [13], in this study, we evaluated whether PJ might confer protection against the olfactory deficits. It has been found that ROT injection caused striatal denervation and related DA and DOPAC depletion as well as loss of DAergic neurons in the olfactory bulb that were associated with motor and olfactory impairments [9]. In our study, long-lasting exposure to ROT induced olfactory deficits quantitatively expressed as a decreased DI value. This is consistent with previous work by Rodrigues et al. (2014), who demonstrated the occurrence of a strong association between nigrostriatal DA level and olfactory discrimination capacity [7]. Importantly, PJ treatment prevented the development of PD-like behavioral deficits in ROT-intoxicated rats. EA, a component of PJ, has been reported to alleviate other nonmotor symptoms, including hyperalgesia, cognitive deficiency, and memory performance in the 6-OHDA-induced rat model of PD [46,47]. Accumulating evidence supports the beneficial effect of treatment with EA, pomegranate's natural precursor of UA, against DAergic neuronal loss and related DA depletion and motor and non-motor dysfunctions in PD models [41-44]. Recently, it has been demonstrated that treatment with extract of Eclipta alba rich in EA significantly downregulated the overexpression of $\alpha$-synuclein at both protein and mRNA levels in the midbrain, prevented loss of DAergic neurons in SNpc, and mitigated behavioral deficits in the MPP+-mediated PD rat model [47].

Our previous findings revealed that UA, the ellagic acid metabolite, is distributed to the brain of PJ-treated rats [13]. In this work, we have demonstrated that PJ treatment prevented the development of PD-like olfactory impairment, slightly mitigated a motor deficit, and preserved DA depletion in ROT-lesioned rats that was accompanied by the presence of UA in their brains. Our findings provide new insights into the beneficial effects of pomegranate juice treatment against $\mathrm{PD}$. Therefore, further studies on plausible mechanisms, including the involvement of UA, that might account for the reported neuroprotective action of pomegranate juice are needed. Since from a neuropathological point of view, both $\mathrm{PD}$ and $\mathrm{AD}$ are proteinopathies with a long prodromal period characterized by hyposmia [48], it could be suggested that UA may also show potential against impaired olfaction caused by beta-amyloid deposition and a neurofibrillary tangle of the tau formation in the olfactory tract.

\section{Conclusions}

Chronic administration of pomegranate juice prevented dopamine depletion, thereby delaying onset and reducing PD symptoms in rats. Urolithin A, a putative active metabolite formed upon pomegranate juice administration, probably contributed to this effect.

Author Contributions: M.K., conceptualization, in vivo experiment, behavioral tests, isolation of urolithin A, dopamine and DOPAC, analysis and interpretation, obtaining financing, and manuscript preparation; M.J., UPLC-ESI-QTOF-MS analysis and its results analysis, interpretation and presentation; Ł.W.; behavioral tests; M.K.-Ł., UPLC-MS/MS analysis of DA and DOPAC; M.S., behavior tests; A.G. isolation of dopamine and DOPAC; P.Ł.M., behavioral tests planning, P.-L.T., writing-review; J.J.-L., supervision of in vivo study and manuscript preparation supervision. All authors have read and agreed to the published version of the manuscript.

Funding: This research was funded by Narodowe Centrum Nauki, grant number UMO-2017/26/D/ NZ7/00748 and The APC was funded by Poznan University of Medical Sciences.

Institutional Review Board Statement: The experiment was performed in accordance with Polish governmental regulations (Dz. U. 05.33.289) and with EU Directive 2010/63/EU for animal experiments. The study protocol was approved by the Local Ethics Committee on the Use of Laboratory Animals in Poznan, Poland (14/2018, 27 April 2018).

Informed Consent Statement: Not applicable.

Data Availability Statement: The datasets analyzed during the current study are available from the corresponding author on reasonable request. 
Conflicts of Interest: The authors declare no conflict of interest.

\section{References}

1. Kalia, L.V.; Lang, A.E. Parkinson's disease. Lancet 2015, 386, 896-912. [CrossRef]

2. Kujawska, M.; Jodynis-Liebert, J. What is the Evidence That Parkinson's Disease is a Prion Disorder, Which Originates in the Gut? Int. J. Mol. Sci. 2018, 19, 3573. [CrossRef] [PubMed]

3. Melis, M.; Haehner, A.; Mastinu, M.; Hummel, T.; Tomassini Barbarossa, I. Molecular and Genetic Factors Involved in Olfactory and Gustatory Deficits and Associations with Microbiota in Parkinson's Disease. Int. J. Mol. Sci. 2021, 22, 4286. [CrossRef]

4. Hawkes, C.H.; Del Tredici, K.; Braak, H. A timeline for Parkinson's disease. Parkinsonism Relat. Disord. 2010, 16, 79-84. [CrossRef] [PubMed]

5. Haehner, A.; Hummel, T.; Reichmann, H. A clinical approach towards smell loss in Parkinson's disease. J. Parkinsons Dis. 2014, 4 189-195. [CrossRef] [PubMed]

6. Aurich, M.F.; Rodrigues, L.S.; Targa, A.D.S.; Noseda, A.C.D.; Cunha, F.D.W.; Lima, M.M.S. Olfactory impairment is related to REM sleep deprivation in rotenone model of Parkinson's disease. Sleep Sci. 2017, 10, 47-54. [CrossRef] [PubMed]

7. Rodrigues, L.S.; Targa, A.D.; Noseda, A.C.; Aurich, M.F.; Da Cunha, C.; Lima, M.M. Olfactory impairment in the rotenone model of Parkinson's disease is associated with bulbar dopaminergic D2 activity after REM sleep deprivation. Front. Cell. Neurosci. 2014, 8, 383. [CrossRef]

8. Valle-Leija, P.; Drucker-Colín, R. Unilateral olfactory deficit in a hemiparkinson's disease mouse model. Neuroreport 2014, 25, 948-953. [CrossRef]

9. Zhang, S.; Xiao, Q.; Le, W. Olfactory dysfunction and neurotransmitter disturbance in olfactory bulb of transgenic mice expressing human A53T mutant $\alpha$-synuclein. PLoS ONE 2015, 10, e0119928. [CrossRef] [PubMed]

10. Höglinger, G.U.; Alvarez-Fischer, D.; Arias-Carrión, O.; Djufri, M.; Windolph, A.; Keber, U.; Borta, A.; Ries, V.; Schwarting, R.K.; Scheller, D.; et al. A new dopaminergic nigro-olfactory projection. Acta Neuropathol. 2015, 130, 333-348. [CrossRef]

11. Belvisi, D.; Pellicciari, R.; Fabbrini, A.; Costanzo, M.; Pietracupa, S.; De Lucia, M.; Modugno, N.; Magrinelli, F.; Dallocchio, C.; Ercoli, T.; et al. Risk factors of Parkinson disease: Simultaneous assessment, interactions, and etiologic subtypes. Neurology 2020, 95, e2500-e2508. [CrossRef]

12. Vegara, S.; Martí, N.; Lorente, J.; Coll, L.; Streitenberger, S.; Valero, M.; Saura, D. Chemical guide parameters for Punica granatum cv. 'Mollar' fruit juices processed at industrial scale. Food Chem. 2014, 147, 203-208. [CrossRef]

13. Kujawska, M.; Jourdes, M.; Kurpik, M.; Szulc, M.; Szaefer, H.; Chmielarz, P.; Kreiner, G.; Krajka-Kuźniak, V.; Mikołajczak, P.; Teissedre, P.L.; et al. Neuroprotective Effects of Pomegranate Juice against Parkinson's Disease and Presence of EllagitanninsDerived Metabolite-Urolithin A-In the Brain. Int. J. Mol. Sci. 2019, 21, 202. [CrossRef] [PubMed]

14. Loren, D.J.; Seeram, N.P.; Schulman, R.N.; Holtzman, D.M. Maternal dietary supplementation with pomegranate juice is neuroprotective in an animal model of neonatal hypoxic-ischemic brain injury. Pediatr. Res. 2005, 57, 858-864. [CrossRef] [PubMed]

15. West, T.; Atzeva, M.; Holtzman, D.M. Pomegranate polyphenols and resveratrol protect the neonatal brain against hypoxicischemic injury. Dev. Neurosci. 2007, 29, 363-372. [CrossRef] [PubMed]

16. Ahmed, M.A.; El Morsy, E.M.; Ahmed, A.A. Pomegranate extract protects against cerebral ischemia/reperfusion injury and preserves brain DNA integrity in rats. Life Sci. 2014, 110, 61-69. [CrossRef]

17. Ahmed, A.H.; Subaiea, G.M.; Eid, A.; Li, L.; Seeram, N.P.; Zawia, N.H. Pomegranate extract modulates processing of amyloid- $\beta$ precursor protein in an aged Alzheimer's disease animal model. Curr. Alzheimer Res. 2014, 11, 834-843. [CrossRef]

18. Essa, M.M.; Subash, S.; Akbar, M.; Al-Adawi, S.; Guillemin, G.J. Long-term dietary supplementation of pomegranates, figs and dates alleviate neuroinflammation in a transgenic mouse model of Alzheimer's disease. PLoS ONE 2015, 10, e0120964. [CrossRef]

19. Yuan, T.; Ma, H.; Liu, W.; Niesen, D.B.; Shah, N.; Crews, R.; Rose, K.N.; Vattem, D.A.; Seeram, N.P. Pomegranate's Neuroprotective Effects against Alzheimer's Disease Are Mediated by Urolithins, Its Ellagitannin-Gut Microbial Derived Metabolites. ACS Chem. Neurosci. 2016, 7, 26-33. [CrossRef]

20. Hartman, R.E.; Shah, A.; Fagan, A.M.; Schwetye, K.E.; Parsadanian, M.; Schulman, R.N.; Finn, M.B.; Holtzman, D.M. Pomegranate juice decreases amyloid load and improves behavior in a mouse model of Alzheimer's disease. Neurobiol. Dis. 2006, 24, 506-515. [CrossRef]

21. Subash, S.; Braidy, N.; Essa, M.M.; Zayana, A.B.; Ragini, V.; Al-Adawi, S.; Al-Asmi, A.; Guillemin, G.J. Long-term (15 mo) dietary supplementation with pomegranates from Oman attenuates cognitive and behavioral deficits in a transgenic mice model of Alzheimer's disease. Nutrition 2015, 31, 223-229. [CrossRef]

22. Subash, S.; Essa, M.M.; Al-Asmi, A.; Al-Adawi, S.; Vaishnav, R.; Braidy, N.; Manivasagam, T.; Guillemin, G.J. Pomegranate from Oman Alleviates the Brain Oxidative Damage in Transgenic Mouse Model of Alzheimer's disease. J. Tradit. Complement. Med. 2014, 4, 232-238. [CrossRef]

23. Rojanathammanee, L.; Puig, K.L.; Combs, C.K. Pomegranate polyphenols and extract inhibit nuclear factor of activated T-cell activity and microglial activation in vitro and in a transgenic mouse model of Alzheimer disease. J. Nutr. 2013, 143, 597-605. [CrossRef]

24. Fathy, S.M.; El-Dash, H.A.; Said, N.I. Neuroprotective effects of pomegranate (Punica granatum L.) juice and seed extract in paraquat-induced mouse model of Parkinson's disease. BMC Complement. Med. Ther. 2021, 21, 130. [CrossRef] 
25. Sarah, R.; Mahsa Hadipour, J. Potential Effects of Pomegranate Juice in Attenuating LID in Mice Model of Parkinson Disease. Pharmacogn. J. 2018, 10, 700-704.

26. Lee, H.J.; Jung, Y.H.; Choi, G.E.; Kim, J.S.; Chae, C.W.; Lim, J.R.; Kim, S.Y.; Yoon, J.H.; Cho, J.H.; Lee, S.J.; et al. Urolithin A suppresses high glucose-induced neuronal amyloidogenesis by modulating TGM2-dependent ER-mitochondria contacts and calcium homeostasis. Cell Death Differ. 2021, 28, 184-202. [CrossRef]

27. Chen, P.; Chen, F.; Lei, J.; Li, Q.; Zhou, B. Activation of the miR-34a-Mediated SIRT1/mTOR Signaling Pathway by Urolithin A Attenuates D-Galactose-Induced Brain Aging in Mice. Neurotherapeutics 2019, 16, 1269-1282. [CrossRef] [PubMed]

28. Gong, Z.; Huang, J.; Xu, B.; Ou, Z.; Zhang, L.; Lin, X.; Ye, X.; Kong, X.; Long, D.; Sun, X.; et al. Urolithin A attenuates memory impairment and neuroinflammation in APP/PS1 mice. J. Neuroinflamm. 2019, 16, 62. [CrossRef]

29. Najmanová, V.; Rambousek, L.; Syslová, K.; Bubeníková, V.; Šlamberová, R.; Valeš, K.; Kačer, P. LC-ESI-MS-MS Method for Monitoring Dopamine, Serotonin and Their Metabolites in Brain Tissue. Chromatographia 2011, 73, 143-149. [CrossRef]

30. Nuñez-Sánchez, M.A.; García-Villalba, R.; Monedero-Saiz, T.; García-Talavera, N.V.; Gómez-Sánchez, M.B.; Sánchez-Álvarez, C.; García-Albert, A.M.; Rodríguez-Gil, F.J.; Ruiz-Marín, M.; Pastor-Quirante, F.A.; et al. Targeted metabolic profiling of pomegranate polyphenols and urolithins in plasma, urine and colon tissues from colorectal cancer patients. Mol. Nutr. Food Res. 2014, 58, 1199-1211. [CrossRef]

31. Seeram, N.P.; Henning, S.M.; Zhang, Y.; Suchard, M.; Li, Z.; Heber, D. Pomegranate juice ellagitannin metabolites are present in human plasma and some persist in urine for up to 48 hours. J. Nutr. 2006, 136, 2481-2485. [CrossRef]

32. Bloem, B.R.; Okun, M.S.; Klein, C. Parkinson's disease. Lancet 2021, 397, 2284-2303. [CrossRef]

33. Cannon, J.R.; Tapias, V.; Na, H.M.; Honick, A.S.; Drolet, R.E.; Greenamyre, J.T. A highly reproducible rotenone model of Parkinson's disease. Neurobiol. Dis. 2009, 34, 279-290. [CrossRef] [PubMed]

34. Heinz, S.; Freyberger, A.; Lawrenz, B.; Schladt, L.; Schmuck, G.; Ellinger-Ziegelbauer, H. Mechanistic Investigations of the Mitochondrial Complex I Inhibitor Rotenone in the Context of Pharmacological and Safety Evaluation. Sci. Rep. 2017, 7, 45465. [CrossRef] [PubMed]

35. Goldstein, D.S.; Holmes, C.; Sullivan, P.; Jinsmaa, Y.; Kopin, I.J.; Sharabi, Y. Elevated cerebrospinal fluid ratios of cysteinyldopamine/3,4-dihydroxyphenylacetic acid in parkinsonian synucleinopathies. Parkinsonism Relat. Disord. 2016, 31, 79-86. [CrossRef] [PubMed]

36. Zaitone, S.A.; Abo-Elmatty, D.M.; Elshazly, S.M. Piracetam and vinpocetine ameliorate rotenone-induced Parkinsonism in rats. Indian J. Pharmacol. 2012, 44, 774-779. [CrossRef] [PubMed]

37. Zaitone, S.A.; Abo-Elmatty, D.M.; Shaalan, A.A. Acetyl-L-carnitine and $\alpha$-lipoic acid affect rotenone-induced damage in nigral dopaminergic neurons of rat brain, implication for Parkinson's disease therapy. Pharmacol. Biochem. Behav. 2012, 100, 347-360. [CrossRef] [PubMed]

38. El-Ghaiesh, S.H.; Bahr, H.I.; Ibrahiem, A.T.; Ghorab, D.; Alomar, S.Y.; Farag, N.E.; Zaitone, S.A. Metformin Protects From Rotenone-Induced Nigrostriatal Neuronal Death in Adult Mice by Activating AMPK-FOXO3 Signaling and Mitigation of Angiogenesis. Front. Mol. Neurosci. 2020, 13, 84. [CrossRef]

39. Zhang, L.; Hao, J.; Zheng, Y.; Su, R.; Liao, Y.; Gong, X.; Liu, L.; Wang, X. Fucoidan Protects Dopaminergic Neurons by Enhancing the Mitochondrial Function in a Rotenone-induced Rat Model of Parkinson's Disease. Aging Dis. 2018, 9, 590-604. [CrossRef]

40. Wei, Y.Z.; Zhu, G.F.; Zheng, C.Q.; Li, J.J.; Sheng, S.; Li, D.D.; Wang, G.Q.; Zhang, F. Ellagic acid protects dopamine neurons from rotenone-induced neurotoxicity via activation of Nrf2 signalling. J. Cell Mol. Med. 2020, 24, 9446-9456. [CrossRef]

41. He, X.M.; Zhou, Y.Z.; Sheng, S.; Li, J.J.; Wang, G.Q.; Zhang, F. Ellagic Acid Protects Dopamine Neurons via Inhibition of NLRP3 Inflammasome Activation in Microglia. Oxid. Med. Cell. Longev. 2020, 2020, 2963540. [CrossRef] [PubMed]

42. Baluchnejadmojarad, T.; Rabiee, N.; Zabihnejad, S.; Roghani, M. Ellagic acid exerts protective effect in intrastriatal 6hydroxydopamine rat model of Parkinson's disease: Possible involvement of ER $\beta / \mathrm{Nrf} 2 / \mathrm{HO}-1$ signaling. Brain Res. 2017, 1662, 23-30. [CrossRef] [PubMed]

43. Sarkaki, A.; Farbood, Y.; Dolatshahi, M.; Mansouri, S.M.; Khodadadi, A. Neuroprotective Effects of Ellagic Acid in a Rat Model of Parkinson's Disease. Acta Med. Iran. 2016, 54, 494-502. [PubMed]

44. Tancheva, L.P.; Lazarova, M.I.; Alexandrova, A.V.; Dragomanova, S.T.; Nicoletti, F.; Tzvetanova, E.R.; Hodzhev, Y.K.; Kalfin, R.E.; Miteva, S.A.; Mazzon, E.; et al. Neuroprotective Mechanisms of Three Natural Antioxidants on a Rat Model of Parkinson's Disease: A Comparative Study. Antioxidants 2020, 9, 49. [CrossRef]

45. Mundiñano, I.C.; Hernandez, M.; Dicaudo, C.; Ordoñez, C.; Marcilla, I.; Tuñon, M.T.; Luquin, M.R. Reduced cholinergic olfactory centrifugal inputs in patients with neurodegenerative disorders and MPTP-treated monkeys. Acta Neuropathol. 2013, 126, 411-425. [CrossRef]

46. Dolatshahi, M.; Farbood, Y.; Sarkaki, A.; Mansouri, S.M.; Khodadadi, A. Ellagic acid improves hyperalgesia and cognitive deficiency in 6-hydroxidopamine induced rat model of Parkinson's disease. Iran. J. Basic Med. Sci. 2015, 18, 38-46.

47. Bhatia, G.; Singh, J.; Nehru, B. Neuroprotective effects of hydro-alcoholic extract of Eclipta alba against 1-methyl-4phenylpyridinium-induced in vitro and in vivo models of Parkinson's disease. Environ. Sci. Pollut. Res. Int. 2021, 28, 9390-9406. [CrossRef]

48. Ubeda-Bañon, I.; Saiz-Sanchez, D.; Flores-Cuadrado, A.; Rioja-Corroto, E.; Gonzalez-Rodriguez, M.; Villar-Conde, S.; AstilleroLopez, V.; Cabello-de la Rosa, J.P.; Gallardo-Alcañiz, M.J.; Vaamonde-Gamo, J.; et al. The human olfactory system in two proteinopathies: Alzheimer's and Parkinson's diseases. Transl. Neurodegener. 2020, 9, 22. [CrossRef] 